Check for updates

Cite this: Chem. Sci., 2018, 9, 7673

๑ All publication charges for this article have been paid for by the Royal Society of Chemistry

Received 23rd June 2018

Accepted 14th August 2018

DOI: $10.1039 / c 8 s c 02768 d$

rsc.li/chemical-science

\title{
A $\beta$-diketiminate manganese catalyst for alkene hydrosilylation: substrate scope, silicone preparation, and mechanistic insight $\uparrow$
}

\author{
Tufan K. Mukhopadhyay, Marco Flores, (D) Thomas L. Groy and Ryan J. Trovitch (D)*
}

The dimeric $\beta$-diketiminate manganese hydride compound, $[(2,6-\mathrm{Pr} 2 \mathrm{Ph} B \mathrm{BDI}) \mathrm{Mn}(\mu-\mathrm{H})]_{2}$, was prepared by treating $[(2,6-i \operatorname{Pr} 2 \mathrm{Ph} B D I) \mathrm{Mn}(\mu-\mathrm{Cl})]_{2}$ with $\mathrm{NaEt}_{3} \mathrm{BH}$. This compound was characterized by single crystal X-ray diffraction and found to feature high-spin $\mathrm{Mn}$ centres that exhibit strong magnetic coupling by EPR spectroscopy. Once characterized, $\left[\left({ }^{2,6-i \operatorname{Pr} 2 \mathrm{Ph}} \mathrm{BDI}\right) \mathrm{Mn}(\mu-\mathrm{H})\right]_{2}$ was found to mediate the hydrosilylation of a broad scope of alkenes at elevated temperature. Aliphatic alkenes were found to undergo anti-Markovnikov hydrosilylation, while the hydrosilylation of styrenes using $\left[\left({ }^{2,6-i \operatorname{Pr} 2 \mathrm{Ph}} \mathrm{BDI}\right) \mathrm{Mn}(\mu-\mathrm{H})\right]_{2}$ afforded Markovnikov's product. Importantly, this catalyst has also been employed for the cross-linking of industrially-relevant silicones derived from vinyl-terminated poly(dimethylsiloxane) and 1,2,4-trivinylcyclohexane with catalyst loadings as low as $0.05 \mathrm{~mol} \%$. To gain a mechanistic understanding of $[(2,6-\mathrm{Pr} 2 \mathrm{Ph} B D I) \mathrm{Mn}(\mu-\mathrm{H})]_{2}$-catalyzed olefin hydrosilylation, 4-tert-butylstyrene was added to $[(2,6-\mathrm{Pr} 2 \mathrm{Ph} B \mathrm{BDI}) \mathrm{Mn}(\mu-\mathrm{H})]_{2}$ and conversion to the monomeric $\mathrm{Mn}$ alkyl complex, ( $\left.{ }^{2,6-\mathrm{Pr} 2 \mathrm{Ph}} \mathrm{BDI}\right) \mathrm{Mn}\left(\mathrm{CH}\left(\mathrm{CH}_{3}\right)\left(4-{ }^{t} \mathrm{BuPh}\right)\right)$, was observed. Isolation of this secondary alkyl intermediate confirms that olefin insertion into the $\mathrm{Mn}-\mathrm{H}$ bond dictates the observed regioselectivities. The importance of our mechanistic findings as they relate to recent advances in $\mathrm{Mn}$ hydrosilylation catalysis is described herein.

\section{Introduction}

The hydrosilylation of alkenes in the presence of hydridefunctionalized siloxanes allows for the industrial preparation of silicones, which commonly serve as release coatings and waterrepellent adhesives. ${ }^{\mathbf{1 , 2}}$ Moreover, silicones are used to prepare a wide variety of consumer products ${ }^{3}$ and are of vital importance to the health care industry given their use in medical grade tubing. ${ }^{4}$ Industrial silicone synthesis is largely dependent on the application of Pt hydrosilylation catalysts; however, there are major disadvantages associated with using a precious metal for this purpose. Since Pt is not widely abundant in Earth's crust $\left(0.005 \mathrm{mg} \mathrm{kg}^{-1}\right),{ }^{5}$ it is costly to obtain and its relative scarcity has led to wild fluctuations in Pt futures pricing. ${ }^{6}$ More importantly, after silicones cure, Pt remains in the product and cannot be easily recovered. ${ }^{6}$ In 2007 alone, it was estimated that 5.6 tonnes of Pt were consumed for the purpose of silicone cross-linking. ${ }^{7}$ Moreover, the residual Pt in silicones is toxic, which has caused side-effects in patients living with silicone implants. ${ }^{8}$

School of Molecular Sciences, Arizona State University, Tempe, AZ 85287, USA. E-mail: ryan.trovitch@asu.edu

$\dagger$ Electronic supplementary information (ESI) available: Metrical parameters for $\mathbf{1}$ and 2, catalytic procedures, and NMR spectroscopic identification of products. CCDC 1851177 and 1851178 For ESI and crystallographic data in CIF or other electronic format see DOI: 10.1039/c8sc02768d
Given the Earth-abundance and biologically-benign nature of late first row transition metals, hydrosilylation catalysts featuring them have emerged as promising and sustainable substitutes. ${ }^{\mathbf{9}, 10}$ Significant progress has been made in the design of well-defined $\mathrm{Fe},{ }^{11} \mathrm{Co},{ }^{12}$ and $\mathrm{Ni}^{13}$ olefin hydrosilylation catalysts, some of which have been shown to cure silicones of industrial importance. ${ }^{11 e, \mathbf{1 2 j}, \mathbf{1 3 e}}$ Although $\mathrm{Mn}$ is $38 \times$ more abundant than Co and $12 \times$ more abundant than $\mathrm{Ni},{ }^{5} \mathrm{Mn}$ catalysts have not been widely employed for alkene hydrosilylation. ${ }^{14}$ In 1983, the thermal and photochemical hydrosilylation of 1pentene using $(\mathrm{CO})_{5} \mathrm{MnSiPh}_{3}$ was reported by researchers at GE. ${ }^{15}$ Hilal and co-workers subsequently showed that $\mathrm{Mn}_{2}(\mathrm{CO})_{10}$ hydrosilylates 1-hexene in the presence of $\mathrm{Et}_{3} \mathrm{SiH}$ or $(\mathrm{EtO})_{3} \mathrm{SiH}$ at $40{ }^{\circ} \mathrm{C}^{16}$ and that polysiloxane-supported $\mathrm{Mn}_{2}(\mathrm{CO})_{10}$ hydrosilylates 1-octene using (EtO) $)_{3} \mathrm{SiH}$ under a range of conditions. ${ }^{17}$ The same group also found that an intercalated Mn porphyrin compound catalyzes the same transformation at temperatures as low as $20{ }^{\circ} \mathrm{C} .{ }^{18}$ In 2016, the Shenvi group observed methylenecyclohexane hydrosilylation in the presence of $\mathrm{PhSiH}_{3}$ and $\mathrm{Mn}(\mathrm{dpm})_{3}(\mathrm{dpm}=$ dipivaloylmethane $) .{ }^{19}$ Last year, the $\mathrm{Mn}$ silylene complex (dmpe $)_{2} \mathrm{MnH}\left(\mathrm{Et}_{2} \mathrm{Si}=\mathrm{CHMe}\right)$ was found to achieve approximately 30 turnovers of ethylene hydrosilylation using $\mathrm{Et}_{2} \mathrm{SiH}_{2}$ after $24 \mathrm{~h}$ at $60{ }^{\circ} \mathrm{C}^{20}$ Thomas and co-workers also reported that the 2,6-bis(imino)pyridine (or pyridine diimine, abbreviated as PDI in this manuscript) supported Mn precursor $\left.{ }^{2,6-\mathrm{Et} 2 \mathrm{Ph}} \mathrm{PDI}\right) \mathrm{MnBr}_{2}$ catalyzes 1-octene hydrosilylation in the presence of $\mathrm{PhSiH}_{3}$ following activation with $\mathrm{NaO}^{t} \mathrm{Bu} .{ }^{21}$ In a very 


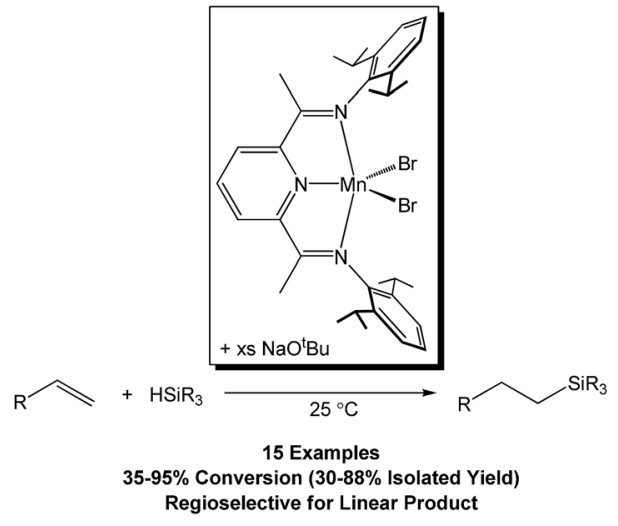

Fig. 1 Alkene hydrosilylation reported by Thomas and co-workers using (2,6-iPr2Ph$P D I) \mathrm{MnBr}_{2}{ }^{22}$

recent follow-on manuscript, ${ }^{22}$ these researchers explored the role of chelate modification on hydrosilylation activity, finding that $2,6-{ }^{\mathrm{i}} \mathrm{Pr}_{2} \mathrm{Ph}$ PDI substitution enhanced catalyst performance. For the first time, they were able to demonstrate a broad substrate scope for the ambient temperature Mn-catalyzed hydrosilylation of aliphatic alkenes to yield linear silanes selectively (Fig. 1). Although poor conversion was noted for the hydrosilylation of styrenes under the preferred reaction conditions (35-40\% after $4 \mathrm{~h}$ at $25^{\circ} \mathrm{C}$ ), these substrates also yielded the anti-Markovnikov product. Importantly, Thomas and coworkers also described mechanistic experiments that suggest a $\mathrm{Mn}-\mathrm{H}$ intermediate may be responsible for the observed catalysis. $^{22}$

Over the last five years, our group has explored the Mncatalyzed hydrosilylation of carbonyl functionalities using donor-substituted chelates. The compounds ( $\left.{ }^{\mathrm{Ph} 2 \mathrm{PPr}} \mathrm{PDI}\right) \mathrm{Mn},{ }^{23}$ ( $\left.{ }^{\mathrm{PyEt}} \mathrm{PDEA}\right) \mathrm{Mn},{ }^{24}\left[\left({ }^{\mathrm{Ph} 2 \mathrm{PEt}} \mathrm{PDI}\right) \mathrm{Mn}\right]_{2},{ }^{25}$ and $\left({ }^{\mathrm{Ph} 2 \mathrm{PPr}} \mathrm{PDI}\right) \mathrm{MnH}^{26}$ have all been found to exhibit exceptional carbonyl hydrosilylation activity; however, they are completely inactive for alkene hydrosilylation at temperatures as high as $120{ }^{\circ} \mathrm{C} .{ }^{27}$ Considering the $\kappa^{4}$ - and $\kappa^{5}$-chelate denticity that these catalysts feature, we have turned our focus to the development of Mn catalysts possessing a more open coordination environment. Herein, we describe the preparation of a $\beta$-diketiminate (BDI, often referred to as NacNac or $\beta$-diiminate) Mn hydride catalyst that has been found to hydrosilylate terminal, cyclic, and gem-alkenes at $130{ }^{\circ} \mathrm{C}$. This catalyst can be used to prepare commercially relevant silicones and stoichiometric addition experiments have revealed that substrate-specific selectivity is dictated by alkene insertion into the $\mathrm{Mn}-\mathrm{H}$ bond.

\section{Results and discussion}

\section{Catalyst synthesis and characterization}

Although a handful of (BDI)Mn compounds have been reported, ${ }^{28}$ none have been evaluated for catalytic alkene hydrosilylation. Therefore, this study commenced with preparation of the bridging chloride complex $\left[\left({ }^{2,6-\mathrm{Pr} 2 \mathrm{Ph}} \mathrm{BDI}\right) \mathrm{Mn}(\mu-\mathrm{Cl})\right]_{2}$ (ref. 28b) (Scheme 1, left) upon reacting in situ generated $[\mathrm{K}]\left[{ }^{2,6-i \operatorname{Pr} 2 \mathrm{Ph}} \mathrm{BDI}\right]$ with $(\mathrm{THF})_{2} \mathrm{MnCl}_{2}$. Adding one equivalent of $\mathrm{NaEt}_{3} \mathrm{BH}$ per $\mathrm{Mn}$ atom
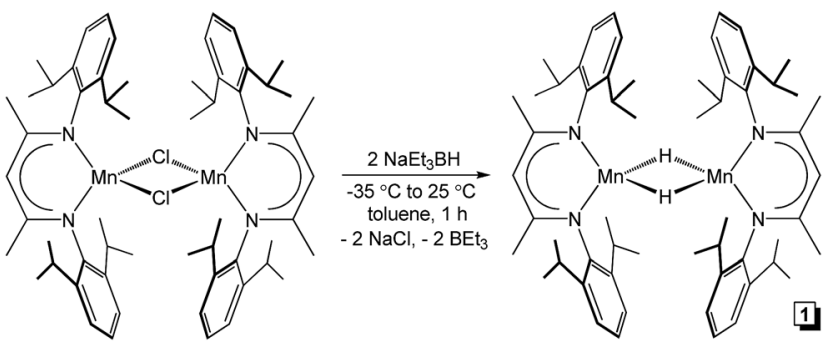

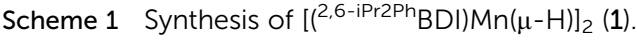

of $\left[\left({ }^{2,6-\mathrm{PPr} 2 \mathrm{Ph}} \mathrm{BDI}\right) \mathrm{Mn}(\mu-\mathrm{Cl})\right]_{2}$ afforded a yellowish-green complex upon warming from -35 to $25{ }^{\circ} \mathrm{C}$ over the course of $1 \mathrm{~h}$, which was identified as $\left[\left({ }^{2,6-\mathrm{iPr} 2 \mathrm{Ph}} \mathrm{BDI}\right) \mathrm{Mn}(\mu-\mathrm{H})\right]_{2}$ (Scheme $\left.1, \mathbf{1}\right)$. The ${ }^{1} \mathrm{H}$ NMR spectrum of this product was found to exhibit broadened resonances over a $25 \mathrm{ppm}$ range and its magnetic susceptibility was determined to be $5.2 \mu_{\mathrm{B}}$ at $298 \mathrm{~K}$ (Evans method), suggesting four unpaired electrons per dimer.

Single crystals of 1 suitable for X-ray diffraction were obtained by cooling a concentrated toluene solution layered with pentane to $-35{ }^{\circ} \mathrm{C}$. The solid-state structure of this compound (Fig. 2) was found to possess a near tetrahedral environment around each $\mathrm{Mn}$ centre, comprised of a $\kappa^{2}$-BDI moiety and two bridging hydride ligands. Notably, the $\mathrm{Mn}-\mathrm{Mn}$ distance of

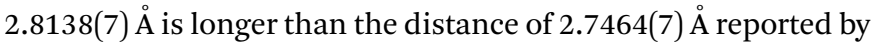
Driess and co-workers for the ethyl-substituted variant, $\left[\left(^{2,6-}\right.\right.$ $\left.\left.{ }^{\mathrm{Et} 2 \mathrm{Ph}} \mathrm{BDI}\right) \mathrm{Mn}(\mu-\mathrm{H})\right]_{2} \cdot{ }^{28 f}$ This difference is likely due to greater steric repulsion between the isopropyl groups of $\mathbf{1}$; however, the Mn centres remain well within bonding distance (the covalent radius of high spin $\mathrm{Mn}$ (II) is approximately $1.61 \AA$ ).${ }^{29}$ A complete list of metrical parameters is provided in Table S2. $\dagger$

To obtain further electronic information, an X-band (9.40 $\mathrm{GHz}$ ) electron paramagnetic resonance (EPR) spectrum of 1 was recorded in a toluene glass at $106 \mathrm{~K}$. The EPR spectrum showed a broad and anisotropic signal extending over $800 \mathrm{mT}$ (Fig. 3). Analogous spectra have previously been reported for dinuclear Mn(II) systems in both small molecules ${ }^{30}$ and proteins. ${ }^{31}$ The observed spectral features correspond to complexes in which the two Mn(II) centres are strongly antiferromagnetically

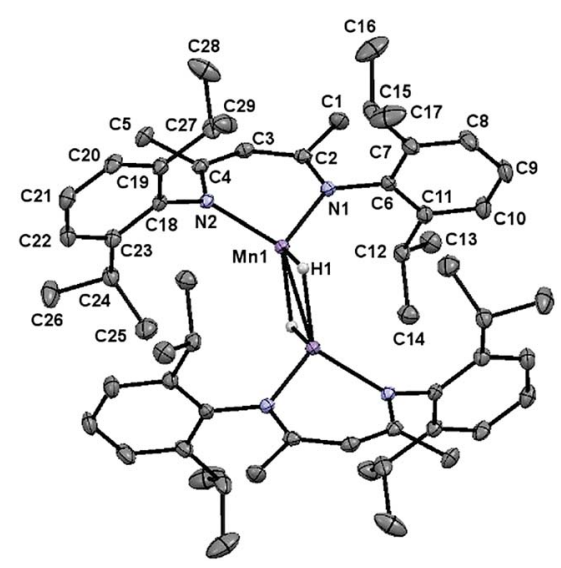

Fig. 2 The solid-state structure of 1 shown with 30\% probability ellipsoids. 


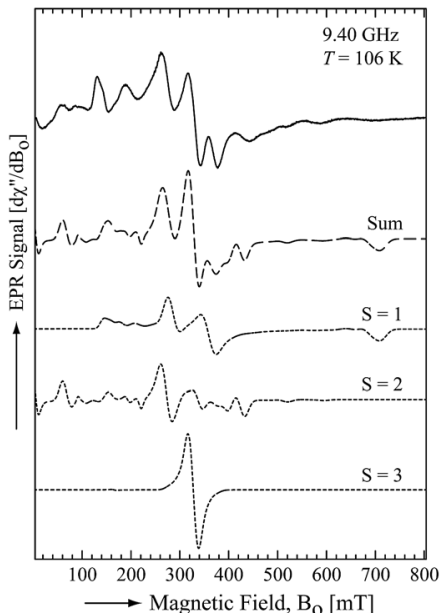

Fig. 3 The X-band EPR spectrum of 1 at $106 \mathrm{~K}$. The solid line is the experimentally determined spectrum and the dashed line is the sum of the simulated spectra for different dimer spin states (dotted lines).

coupled (i.e. $\left|J_{\mathrm{o}}\right| \gg g_{\mathrm{i}} \beta_{\mathrm{e}} \mathrm{B}_{\mathrm{o}}$ ). The EPR spectrum was simulated using a spin Hamiltonian that included the Zeeman and zerofield splitting (ZFS) interactions of the individual $\mathrm{Mn}$ (II) $\left(S_{i}=\right.$ $5 / 2$ ) sites within the dimer and the dipole-dipole interaction between the two Mn(II) sites of the dimer. The best fit was obtained considering the EPR transitions corresponding to the total spin manifolds $S=1,2$ and 3 (Fig. 3). The parameters obtained from the fit are summarized in Table 1 . As expected for high-spin $\mathrm{Mn}(\mathrm{II})$ centres, an isotropic $g$-value $\left(g_{\text {iso }}=2.05\right)$ and small ZFS parameters (i.e. $|D|<0.1 \mathrm{~cm}^{-1}$ ) were obtained. The principal components of the dipole-dipole interaction tensor are relatively large and significantly deviated from axial symmetry due to the close proximity of the two Mn(II) centres.

\section{Alkene hydrosilylation}

Having characterized 1, its ability to catalyze olefin hydrosilylation was evaluated. Although this catalyst was ineffective at lower temperatures, equimolar addition of 1-hexene (Table 2, a)

Table 1 Parameters used to fit the EPR spectrum of 1 in a toluene glass at $9.40 \mathrm{GHz}$ and $T=106 \mathrm{~K}$

\begin{tabular}{ll}
\hline Parameter $^{a}$ & $\mathbf{1}$ \\
\hline$g_{\text {iso }}$ & 2.05 \\
$|D|\left(\mathrm{cm}^{-1}\right)$ & 0.0932 \\
$|E|\left(\mathrm{cm}^{-1}\right)$ & 0.0129 \\
$J_{\mathrm{o}}\left(\mathrm{cm}^{-1}\right)$ & n.d. \\
$J_{x^{\prime}}\left(\mathrm{cm}^{-1}\right)$ & -0.0089 \\
$J_{y^{\prime}}\left(\mathrm{cm}^{-1}\right)$ & -0.0036 \\
$J_{z^{\prime}}\left(\mathrm{cm}^{-1}\right)$ & 0.0125 \\
$\Delta B(\mathrm{MHz})$ & 600
\end{tabular}

${ }^{a}$ The fitting parameters were the isotropic $g$-value, $g_{\text {iso }}$, the zero-field splitting parameters, $D$ and $E$, the principal components of the dipole-dipole interaction tensor $\boldsymbol{J}$, (i.e. $J_{x^{\prime}}, J_{y^{\prime}}$, and $J_{z^{\prime}}$ ), and isotropic line width, $\Delta B .{ }^{b} J_{\mathrm{o}}$ is not a fitting parameter of a single spectrum but it can be determined by fitting the temperature dependence of the signal intensities corresponding to $S=1, S=2$, and $S=3$.
Table 2 Hydrosilylation of alkenes with anti-Markovnikov selectivity using $0.5 \mathrm{~mol} \%$ of 1 ( $1.0 \mathrm{~mol} \%$ based on $\mathrm{Mn}$ )

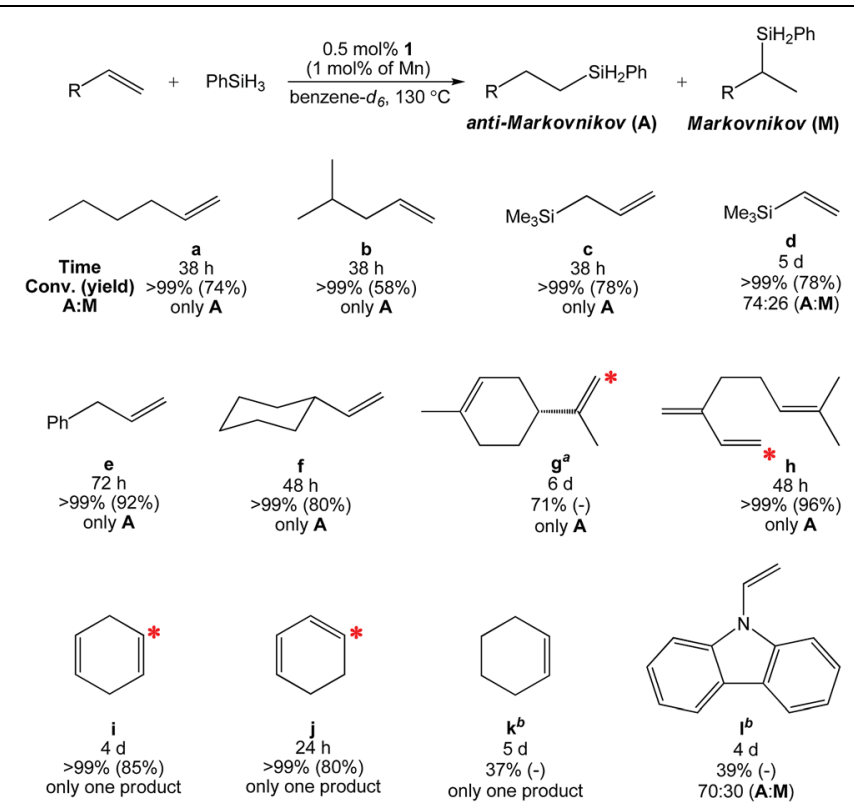

All trials were carried out under $\mathrm{N}_{2}$ atmosphere in a J. Young tube. The red star $(*)$ shows the position of silane incorporation. ${ }^{a}$ The cyclic olefin moiety was untouched over the course of catalysis. ${ }^{b}$ The product was not isolated.

and $\mathrm{PhSiH}_{3}$ to $0.5 \mathrm{~mol} \%$ of $1(1.0 \mathrm{~mol} \%$ based on $\mathrm{Mn})$ in benzene- $d_{6}$ allowed for complete hydrosilylation to yield the anti-Markovnikov (A) product, $n-\mathrm{C}_{6} \mathrm{H}_{13} \mathrm{SiH}_{2} \mathrm{Ph}$, after $38 \mathrm{~h}$ at $130{ }^{\circ} \mathrm{C}$. Under these conditions, the use of $\mathrm{Ph}_{2} \mathrm{SiH}_{2}, \mathrm{Ph}_{3} \mathrm{SiH}$, and (EtO) $)_{3} \mathrm{SiH}$ did not allow for conversion. In the presence of $\mathrm{Et}_{2} \mathrm{SiH}_{2}, 1$ was found to achieve 61\% 1-hexene hydrosilylation after $48 \mathrm{~h}$; however, longer reaction times did not allow for completion. Therefore, $\mathrm{PhSiH}_{3}$ was chosen as the $\mathrm{Si}-\mathrm{H}$ source for further study.

Additional alkenes that lack aromatic substitution were screened for hydrosilylation under identical conditions (Table 2). The hydrosilylation of 4-methyl-1-pentene (b) and allyltrimethylsilane (c) required $38 \mathrm{~h}$ to reach completion, furnishing only the anti-Markovnikov product (A). The olefin functionalities of $\mathrm{d}$-f required longer reaction times, and in the case of vinyltrimethylsilane (d) an $\mathbf{A}: \mathbf{M}$ ratio of $74: 26$ was obtained. The gem-olefin of D-limonene (g) was $71 \%$ hydrosilylated after $6 \mathrm{~d}$, while the cyclic olefin was left untouched. Likewise, the terminal olefin of myrcene (h) was selectively hydrosilylated over the gem and trisubstituted olefins after $48 \mathrm{~h}$ at $130{ }^{\circ} \mathrm{C}$. Interestingly, one olefin of 1,4-cyclohexadiene (i) was hydrosilylated in $4 \mathrm{~d}$ to selectively yield cyclohex-3-en-1yl(phenyl)silane. The conjugated regioisomer, 1,3-cyclohexadiene (j), furnished the same product after $24 \mathrm{~h}$, suggesting that conjugation enhances the rate of hydrosilylation. We subsequently performed the hydrosilylation of $\mathbf{i}$ using $\mathrm{PhSiD}_{3}$ and observed methylene ${ }^{2} \mathrm{H}$ NMR resonances at 1.62 and $1.82 \mathrm{ppm}$, indicating that isomerization occurs under catalytic conditions (Fig. S42†). Cyclohexene (k) afforded only 37\% 
conversion to phenylcyclohexylsilane after $5 \mathrm{~d}$ along with products from dehydrogenative benzene- $d_{6}$ silylation (see Fig. S43 $\dagger$ ). This substrate is less rigid than both 1,4-cyclohexadiene and 1,3-cyclohexadiene indicating that olefin coordination to $\mathrm{Mn}$ influences the rate of conversion. It is believed that entries $\mathbf{i}-\mathbf{k}$ represent the first known examples of $\mathrm{Mn}$ catalyzed cyclic olefin hydrosilylation. For each fully converted substrate, the alkylsilane products were isolated in good yield and purity following filtration and drying.

Given our prior efforts to evaluate Mn catalysts for carbonyl hydrosilylation, ${ }^{23-27}$ we sought to determine the chemoselectivity of 1-mediated 5-hexen-2-one $(\mathbf{m})$ reduction. Immediately upon adding 2.2 equivalents of $\mathrm{PhSiH}_{3}$ to a benzene- $d_{6}$ solution of this substrate and $0.5 \mathrm{~mol} \% 1$ (1.0 mol\% based on $\mathrm{Mn})$, an exothermic reaction ensued and complete carbonyl hydrosilylation was confirmed by ${ }^{1} \mathrm{H}$ NMR spectroscopy after $1.5 \mathrm{~h}$ (Scheme 2). Heating to $130{ }^{\circ} \mathrm{C}$ allowed for greater than $99 \%$ alkene hydrosilylation after $24 \mathrm{~h}$ to yield a mixture of products (Fig. S45†). These results suggest that $\mathbf{1}$ is a highly active catalyst for carbonyl hydrosilylation and that it can selectively reduce carbonyl functionalities over olefins at ambient temperature.

When styrenes were employed as substrates, 1 generated the Markovnikov hydrosilylation product in most cases (Table 3). When styrene (n) was heated to $130{ }^{\circ} \mathrm{C}$ with one equivalent of $\mathrm{PhSiH}_{3}$ and $0.5 \mathrm{~mol} \%$ of 1 (1.0 mol\% based on $\mathrm{Mn}$ ) in benzene$d_{6}$, greater than $99 \%$ conversion was confirmed after 38 h by ${ }^{1} \mathrm{H}$ NMR spectroscopy. Evaporation of the solvent and filtration with pentane allowed for catalyst removal, and drying the filtrate under vacuum yielded a pale yellowish oil containing $89 \% \mathbf{M}$ and $11 \% \mathbf{A}$ silane products. Six additional styrenes were screened under analogous conditions (o-t). Interestingly, trans$\beta$-methylstyrene (q) and cis- $\beta$-methylstyrene (r) were successfully hydrosilylated to form the $\alpha$-silyl product with good selectivity. In contrast, the 1-mediated hydrosilylation of $\alpha$-methylstyrene (s) resulted in only 56\% conversion after $4 \mathrm{~d}$ to form the $\beta$-silyl product. This trial suggests that gem-olefin substitution provides sufficient steric bulk at the $\alpha$-carbon position to disfavor Markovnikov hydrosilylation (vide infra). Although substrates $\mathbf{g}$ and $\mathbf{s}$ were not fully hydrosilylated, they represent

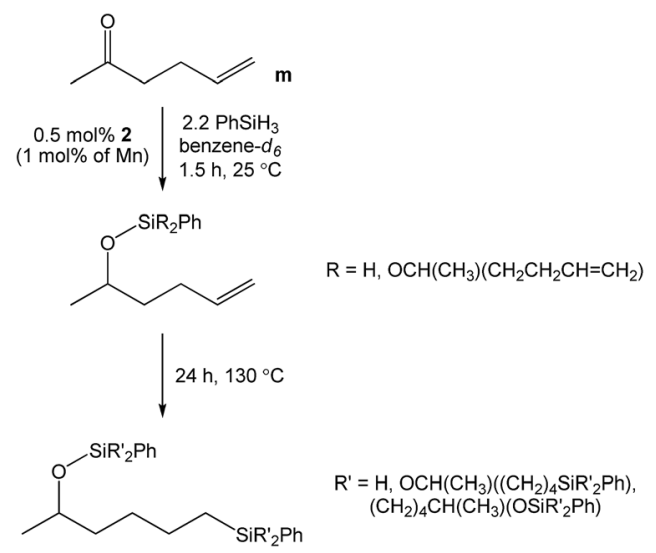

Scheme 2 The stepwise hydrosilylation of 5-hexen-2-one catalysed by 1 .
Table 3 Hydrosilylation of styrenes with Markovnikov selectivity using $0.5 \mathrm{~mol} \%$ of 1 (1.0 mol\% based on $\mathrm{Mn}$ )

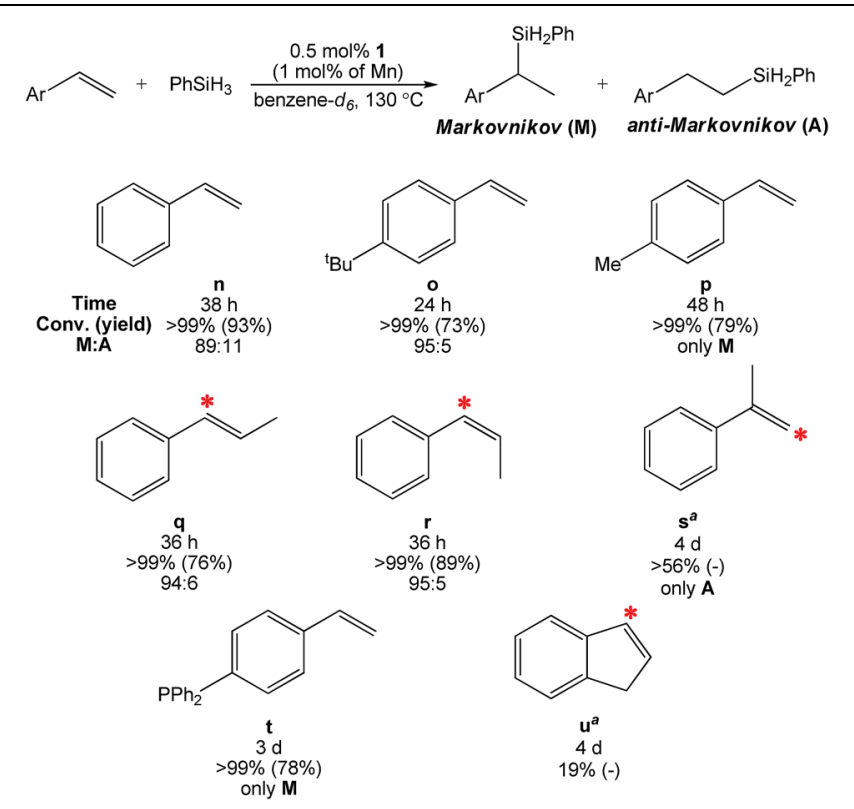

All trials were carried out under $\mathrm{N}_{2}$ atmosphere in a J. Young tube. The red star $\left(^{*}\right)$ shows the position of silane incorporation. ${ }^{a}$ No further conversion was noted after prolonged heating and the products were not isolated.

the second and third known examples of Mn-catalyzed gemolefin hydrosilylation. ${ }^{19}$ Notably, 4-(diphenylphosphino)styrene (t) was completely hydrosilylated in $3 \mathrm{~d}$, indicating that phosphine functionalities are tolerated by 1 . It should be noted that 4-bromostyrene did not show any conversion after $4 \mathrm{~d}$, while 4 fluorostyrene was completely consumed to yield a complex mixture of $\mathbf{M}, \mathbf{A}$, and silylated arene products following defluorination (multiple resonances were observed in the ${ }^{19} \mathrm{~F}$ spectrum, Fig. S76†).

\section{Silicone preparation}

Although 1 requires higher temperatures and is less active than $\left.{ }^{2,6-\mathrm{Pr} 2 \mathrm{Ph}} \mathrm{PDI}\right) \mathrm{MnBr}_{2},{ }^{22}$ attempts were made to utilize our catalyst to prepare silicones that are traditionally synthesized via Ptmediated hydrosilylation. Given that the hydrosilylation of vinyl-terminated poly(dimethylsiloxane)s is conducted industrially to prepare a variety of silicone coatings and materials, ${ }^{13 e}$ $10 \mathrm{~mol} \%$ of 1 relative to this substrate ( $5 \mathrm{~mol} \%$ relative to olefin) was added in the presence of excess polymethylhydrosiloxane (PMHS). Heating this neat mixture at $130{ }^{\circ} \mathrm{C}$ for $5 \mathrm{~d}$ afforded a colourless, gummy silicone solid (Scheme 3, Fig. 4, P-1) after catalyst deactivation and washing with isopropanol.

A polymeric product derived from 1,2,4-trivinylcyclohexane (mixture of isomers) was also targeted, since $\mathbf{1}$ has been shown to hydrosilylate vinylcyclohexane (Table 2, f) in antiMarkovnikov fashion. Notably, silicones prepared via the hydrosilylation of this substrate are used in oxygen permeable contact lenses $^{\mathbf{3 2}}$ and transparent LED screen compositions. ${ }^{33}$ Heating a neat mixture of PMHS and 1,2,4-trivinylcyclohexane 

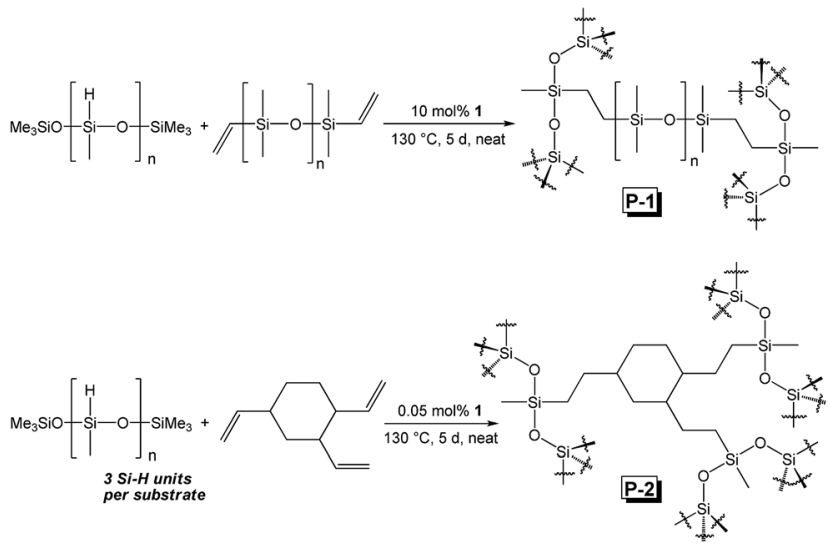

Scheme 3 The preparation of silicones following 1-catalyzed hydrosilylation.

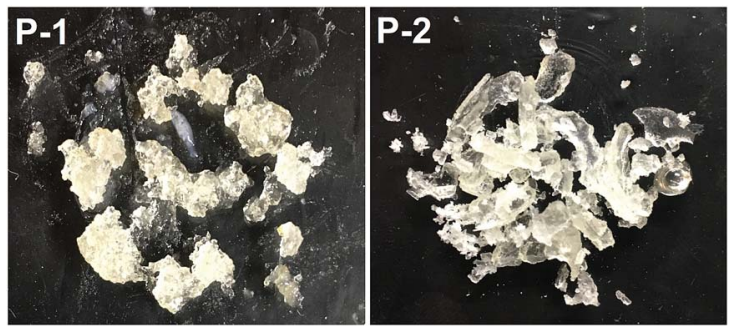

Fig. 4 Silicones prepared following the 1-catalyzed hydrosilylation of vinyl-terminated poly(dimethylsiloxane) (P-1) and 1,2,4-trivinylcyclohexane (P-2) using PMHS.

(1: 1 ratio of $\mathrm{Si}-\mathrm{H}$ to olefin) in the presence of $0.05 \mathrm{~mol} \% 1$ (relative to substrate, $0.0167 \mathrm{~mol} \%$ relative to total alkene count), afforded a colourless and transparent silicone after heating for $5 \mathrm{~d}$ in the absence of solvent (Scheme 3, Fig. 4, P-2). It should be noted that $\mathrm{Du}$ and co-workers have recently described the synthesis of silicones by way of Mn-mediated carbonyl hydrosilylation and dehydrogenative alcohol silylation; ${ }^{34}$ however, $\mathbf{P - 1}$ and $\mathbf{P - 2}$ are believed to be the first silicones featuring non-hydrolysable $\mathrm{Si}-\mathrm{C}$ bonds prepared via $\mathrm{Mn}$ catalysis.

\section{Mechanistic considerations}

To rationalize the substrate-dependent regioselectivity observed for 1-catalysed alkene hydrosilylation, further mechanistic understanding was sought. First, 1 was heated with two equivalents of $\mathrm{PhSiH}_{3}$ (one equivalent per Mn) at $130{ }^{\circ} \mathrm{C}$ for $24 \mathrm{~h}$. The reaction mixture was unchanged as judged by ${ }^{1} \mathrm{H}$ NMR and ${ }^{29} \mathrm{Si}$ NMR spectroscopy and $\mathbf{1}$ was recovered quantitatively following solvent and silane removal. This lack of reactivity suggests that $\sigma$-bond metathesis between the $\mathrm{Si}-\mathrm{H}$ bond of $\mathrm{PhSiH}_{3}$ and the $\mathrm{Mn}-\mathrm{H}$ bond of $\mathbf{1}$ does not occur during catalysis. However, heating 1 in the presence of two equivalents of 4-tert-butylstyrene at $130{ }^{\circ} \mathrm{C}$ for $16 \mathrm{~h}$ yielded a monomeric compound identified as $\left({ }^{2,6-i \operatorname{Pr} 2 \mathrm{Ph}} \mathrm{BDI}\right) \mathrm{Mn}\left(\mathrm{CH}\left(\mathrm{CH}_{3}\right)\left(4{ }^{t} \mathrm{BuPh}\right)\right)$ (Scheme 4, 2). This compound was found to exhibit an ambient temperature

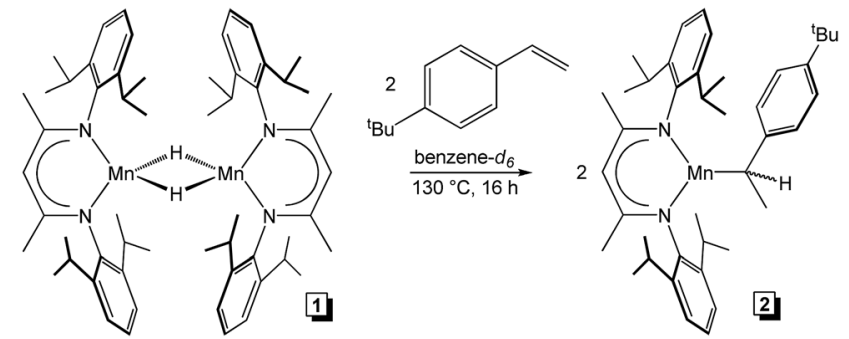

Scheme 4 Addition of 4-tert-butylstyrene to 1 to generate 2 .

magnetic moment of $6.0 \mu_{\mathrm{B}}$, which is consistent with a highspin $\mathrm{Mn}(\mathrm{II})$ electronic structure.

Complex 2 was found to exhibit a new set of paramagnetically broadened ${ }^{1} \mathrm{H}$ NMR resonances over a $25 \mathrm{ppm}$ range and cooling a concentrated $\mathrm{Et}_{2} \mathrm{O}$ solution at $-35{ }^{\circ} \mathrm{C}$ afforded yellow crystals suitable for X-ray diffraction. Importantly, the solid-state structure of 2 possesses a secondary alkyl ligand (Fig. 5, for metrical parameters, see Table S3†). This observation suggests that 1-mediated alkene hydrosilylation proceeds via olefin coordination (with concurrent dimer dissociation) and subsequent insertion into the $\mathrm{Mn}-\mathrm{H}$ bond. Moreover, the fact that 4-tert-butylstyrene insertion generates a secondary alkyl ligand rationalizes the Markovnikov selectivity observed for the styrene substrates in Table 3.

To confirm that 2 is a catalytic intermediate and not a deactivation product, the reactivity of this compound was evaluated. Under the conditions of catalysis, the addition of 1.5 equiv. of $\mathrm{PhSiH}_{3}$ to 2 afforded $\mathbf{1}$ and the respective Markovnikov silane product (Scheme 5). Moreover, compound 2 was evaluated for $\alpha$-olefin and styrene hydrosilylation activity. Adding an equimolar quantity of 1-hexene and $\mathrm{PhSiH}_{3}$ to $1.0 \mathrm{~mol} \%$ of 2 allowed for complete substrate hydrosilylation after $22 \mathrm{~h}$ at $130^{\circ} \mathrm{C}$. Importantly, only A product was observed, which is consistent with the selectivity reported in Table 2 . Likewise, 2-mediated styrene hydrosilylation afforded a $91: 9$ ratio of $\mathbf{M}$ and $\mathbf{A}$ products after only $16 \mathrm{~h}$ at $130{ }^{\circ} \mathrm{C}$. Taken together, these experiments indicate that alkyl intermediates

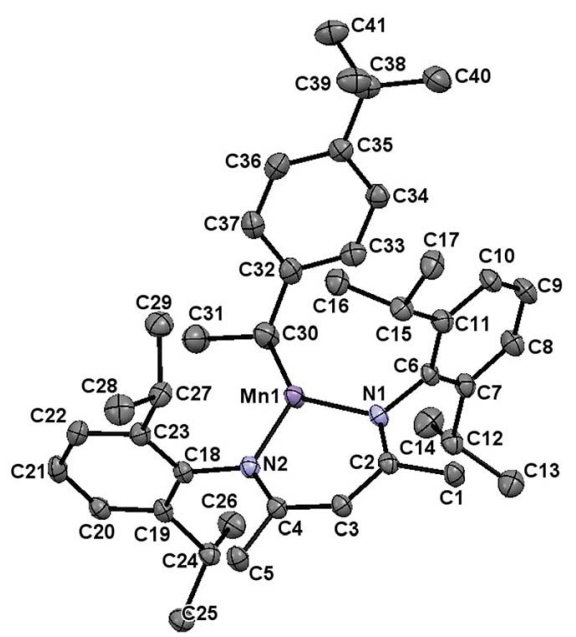

Fig. 5 The solid-state structure of 2 at 30\% probability ellipsoids. 

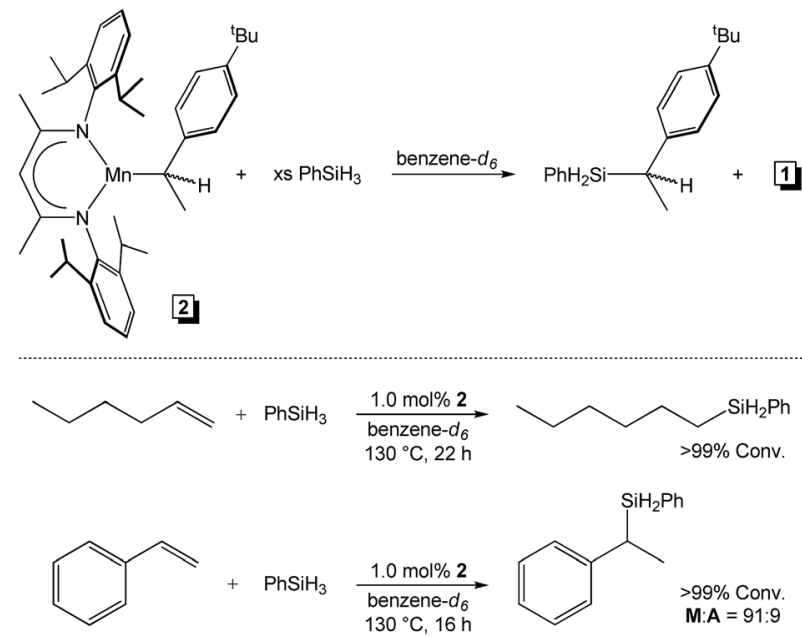

Scheme 5 Addition of $\mathrm{PhSiH}_{3}$ to 2 results in alkylsilane product formation and regeneration of 1 (top) and 2 catalyses 1-hexene and styrene hydrosilylation more efficiently than 1 (bottom).

such as 2 re-enter the catalytic cycle following reaction with $\mathrm{PhSiH}_{3}$ to regenerate 1 .

With these considerations in mind, we propose concurrent mechanistic pathways that differ from the commonly evoked Chalk-Harrod hydrosilylation mechanism (which involves $\mathrm{Si}-\mathrm{H}$ oxidative addition). ${ }^{35}$ Resonances associated with monomeric 1
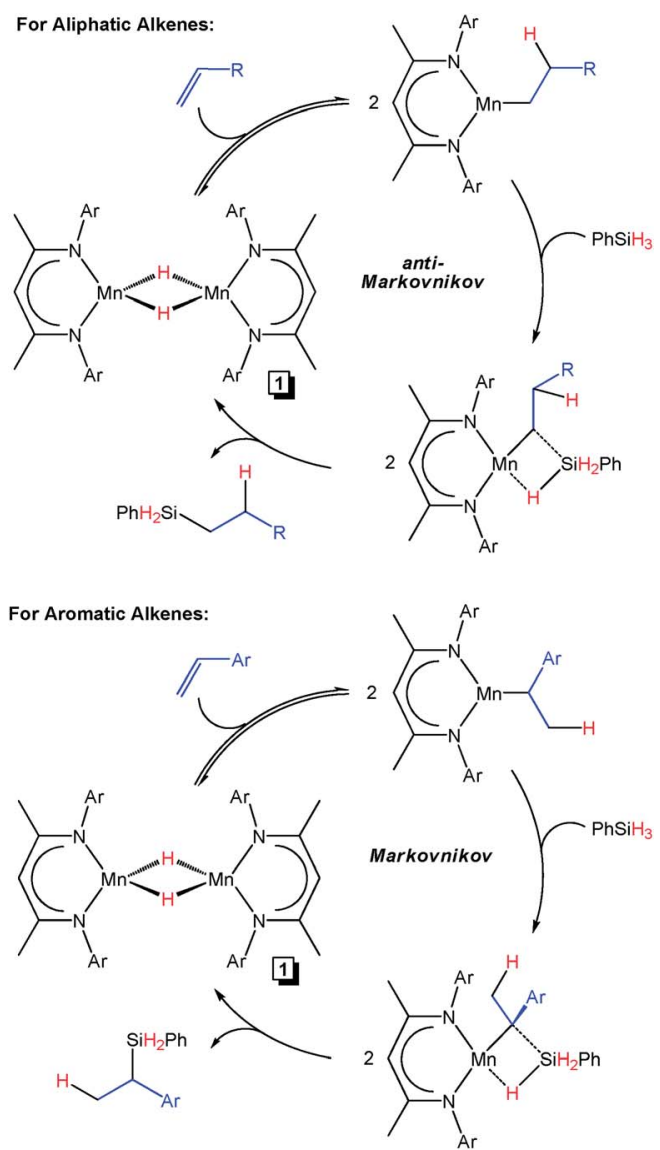

Fig. 6 Proposed mechanisms for 1-catalyzed alkene hydrosilylation. have not been observed by ${ }^{1} \mathrm{H}$ NMR spectroscopy at temperatures of up to $130{ }^{\circ} \mathrm{C}$ in the absence of substrate (Fig. S90 $\dagger$ ). Therefore, for the aliphatic alkenes in Table 1, alkene addition to $\mathbf{1}$ allows for dimer dissociation and insertion into the $\mathrm{Mn}-\mathrm{H}$ bond to generate a primary alkyl intermediate (top right of Fig. 6). In the presence of $\mathrm{PhSiH}_{3}, \sigma$-bond metathesis occurs between the $\mathrm{Si}-\mathrm{H}$ and $\mathrm{Mn}-\mathrm{C}$ bonds to release the linear silane product and regenerate 1. A similar hydrosilylation cycle was reported by Chirik and co-workers for $\left[\left({ }^{2,6-\mathrm{Pr} 2 \mathrm{Ph}} \mathrm{DI}\right) \mathrm{NiH}\right]_{2} ;^{13 e}$ however, it should be noted that $\mathrm{Mn}$ is believed to remain divalent throughout catalysis. In contrast, the styrene substrates in Table 3 (with the exception of $\alpha$-methylstyrene) are electronically predisposed to insert at the benzylic position to generate a secondary alkyl intermediate. ${ }^{36}$ Due to steric constraints, $\alpha$-methylstyrene (s) cannot insert to form a tertiary alkyl intermediate, and it is therefore hydrosilylated via the antiMarkovnikov pathway. The BDI ligand steric environment is less demanding than that of $\left({ }^{2,6-\mathrm{Pr} 2 \mathrm{Ph}} \mathrm{PDI}\right) \mathrm{MnBr}_{2},{ }^{22}$ which may explain why the in situ generated $\mathrm{Mn}-\mathrm{H}$ proposed by Thomas and co-workers selectively yields linear hydrosilylation products.

\section{Conclusions}

Upon preparing and characterizing the well-defined $\beta$-diketiminate manganese hydride compound, $\left[\left({ }^{2,6-\mathrm{iPr} 2 \mathrm{Ph}} \mathrm{BDI}\right) \mathrm{Mn}(\mu-\mathrm{H})\right]_{2}$ (1), its ability to catalyse olefin hydrosilylation was explored. Low loadings of this catalyst $(0.5 \mathrm{~mol} \%)$ have been shown to hydrosilylate 20 different olefinic substrates at $130{ }^{\circ} \mathrm{C}$, including some that are disubstituted. These hydrosilylation trials revealed substrate-specific regioselectivity; 1 was found to catalyse aliphatic alkene hydrosilylation in anti-Markovnikov fashion while styrenes underwent Markovnikov hydrosilylation. Two commercially relevant silicone formation reactions have also been described, both of which afforded colourless polymer following an isopropanol wash. Stoichiometric addition experiments revealed that 4-tert-butylstyrene reacts with 1 to yield a secondary alkyl product, $\left({ }^{2,6-\mathrm{Pr} 2 \mathrm{Ph}} \mathrm{BDI}\right)$ $\mathrm{Mn}\left(\mathrm{CH}\left(\mathrm{CH}_{3}\right)\left(4-{ }^{t} \mathrm{BuPh}\right)\right)(2)$, indicating that the regioselectivity of hydrosilylation is dictated by alkene insertion. This result is consistent with recent experiments by Thomas and co-workers ${ }^{22}$ that suggest alkene insertion into a $\mathrm{Mn}-\mathrm{H}$ intermediate is responsible for $\left({ }^{2,6-\mathrm{iPr} 2 \mathrm{Ph}} \mathrm{PDI}\right) \mathrm{MnBr}_{2}$-mediated olefin hydrosilylation. Taken together, these studies encourage the future utilization of inexpensive and non-toxic manganese catalysts for alkene hydrosilylation and silicone curing transformations.

\section{Conflicts of interest}

The authors declare the following competing financial interests: T. K. M. and R. J. T. retain rights to 1 through US Patent Application No. 62/678,624.

\section{Acknowledgements}

This material is based upon work supported by the National Science Foundation under Grant No. 1651686. 


\section{Notes and references}

1 B. Marciniec, Comprehensive Handbook on Hydrosilylation, Pergamon Press, New York, USA, 1st edn, 1992.

2 D. Troegel and J. Stohrer, Coord. Chem. Rev., 2011, 255, 14401459.

3 Y. Zhang, Adv. J. Food Sci. Technol., 2016, 12, 145-149.

4 S. M. Bahal and J. M. Romansky, Pharm. Dev. Technol., 2002, 7, 317-323.

5 W. M. Haynes, CRC Handbook of Chemistry and Physics: A Ready-reference Book of Chemical and Physical Data, Taylor \& Francis, Boca Raton, FL, 94th edn, 2013-2014.

6 The 10 year futures price for platinum (COMEX) has ranged between $\$ 800$ and $\$ 1,900$ USD per troy ounce. Accessed at: https:/www.nasdaq.com/markets/platinum.aspx? timeframe $=10 \mathrm{y}$.

7 A. J. Holwell, Platinum Met. Rev., 2008, 52, 243-246.

8 E. D. Lykissa and S. V. M. Maharaj, Anal. Chem., 2006, 78, 2925-2933.

9 X. Du and Z. Huang, ACS Catal., 2017, 7, 1227-1243.

10 J. V. Obligacion and P. J. Chirik, Nat. Rev. Chem., 2018, 2, 1534.

11 (a) G. Bellachioma, G. Cardaci, E. Colomer, R. J. P. Corriu and A. Vioux, Inorg. Chem., 1989, 28, 519-525; (b) B. Marciniec and M. Majchrzak, Inorg. Chem. Commun., 2000, 3, 371-375; (c) S. C. Bart, E. Lobkovsky and P. J. Chirik, J. Am. Chem. Soc., 2004, 126, 13794-13807; (d) A. M. Archer, M. W. Bouwkamp, M.-P. Cortez, E. Lobkovsky and P. J. Chirik, Organometallics, 2006, 25, 4269-4278; (e) A. M. Tondreau, C. C. H. Atienza, K. J. Weller, S. A. Nye, K. M. Lewis, J. G. P. Delis and P. J. Chirik, Science, 2012, 335, 567-570; (f) K. Kamata, A. Suzuki, Y. Nakai and H. Nakazawa, Organometallics, 2012, 31, 3825-3828; (g) A. M. Tondreau, C. C. H. Atienza, J. M. Darmon, C. Milsmann, H. M. Hoyt, K. J. Weller, S. A. Nye, K. M. Lewis, J. Boyer, J. G. P. Delis, E. Lobkovsky and P. J. Chirik, Organometallics, 2012, 31, 4886-4893; $(h)$ D. Peng, Y. Zhang, X. Du, L. Zhang, X. Leng, M. D. Walter and Z. Huang, J. Am. Chem. Soc., 2013, 135, 19154-19166; (i) M. D. Greenhalgh, D. J. Frank and S. P. Thomas, Adv. Synth. Catal., 2014, 356, 584-590; (j) J. Chen, B. Cheng, M. Cao and Z. Lu, Angew. Chem., Int. Ed., 2015, 54, 46614664; (k) R. Gilbert-Wilson, W.-Y. Chu and T. B. Rauchfuss, Inorg. Chem., 2015, 54, 5596-5603; (l) B. Marciniec, A. Kownacka, I. Kownacki, M. Hoffmann and R. Taylor, $J$. Organomet. Chem., 2015, 791, 58-65; (m) Y. Sunada, D. Noda, H. Soejima, H. Tsutsumi and H. Nagashima, Organometallics, 2015, 34, 2896-2906; (n) G. I. Nikonov, ChemCatChem, 2015, 7, 1918-1919; (o) X. Jia and Z. Huang, Nat. Chem., 2016, 8, 157-161; (p) D. Noda, A. Tahara, Y. Sunada and H. Nagashima, J. Am. Chem. Soc., 2016, 138, 2480-2483; $(q)$ X. Du, Y. Zhang, D. Peng and Z. Huang, Angew. Chem., Int. Ed., 2016, 55, 6671-6675; (r) A. J. Challinor, M. Calin, G. S. Nichol, N. B. Carter and S. P. Thomas, Adv. Synth. Catal., 2016, 358, 2404-2409; (s) K. Hayasaka, K. Kamata and H. Nakazawa, Nat. Chem.,
2016, 89, 394-404; ( $t$ ) Y. Toya, K. Hayasaka and H. Nakazawa, Organometallics, 2017, 36, 1727-1735; (u) M.-Y. Hu, Q. He, S.-J. Fan, Z.-C. Wang, L.-Y. Liu, Y.-J. Mu, Q. Peng and S.-F. Zhu, Nat. Commun., 2018, 9, 221; (v) B. Cheng, W. Liu and Z. Lu, J. Am. Chem. Soc., 2018, 140, 5014-5017.

12 (a) A. J. Chalk, J. Organomet. Chem., 1970, 21, 207-213; (b) G. K. I. Magomedov, K. A. Andrianov, O. V. Shkolnik, B. A. Izmailov and V. N. Kalinin, J. Organomet. Chem., 1978, 149, 29-36; (c) Y. Seki, K. Kawamoto, N. Chatani, A. Hidaka, N. Sonoda, K. Ohe, Y. Kawasaki and S. Murai, J. Organomet. Chem., 1991, 403, 73-84; (d) M. Brookhart and B. E. Grant, J. Am. Chem. Soc., 1993, 115, 2151-2156; (e) N. Chatani, T. Kodama, Y. Kajikawa, H. Murakami, F. Kakiuchi, S.-I. Ikeda and S. Murai, Chem. Lett., 2000, 29, 14-15; ( $f$ ) C. C. H. Atienza, T. Diao, K. J. Weller, S. A. Nye, K. M. Lewis, J. G. P. Delis, J. L. Boyer, A. K. Roy and P. J. Chirik, J. Am. Chem. Soc., 2014, 136, 12108-12118; $(g)$ C. Chen, M. B. Hecht, A. Kavara, W. W. Brennessel, B. Q. Mercado, D. J. Weix and P. L. Holland, J. Am. Chem. Soc., 2015, 137, 13244-13247; (h) J. Sun and L. Deng, ACS Catal., 2016, 6, 290-300; (i) A. Gorczyński, M. Zaranek, S. Witomska, A. Bocian, A. R. Stefankiewicz, M. Kubicki, V. Patroniak and P. Pawluć, Catal. Commun., 2016, 78, 7174; (j) C. H. Schuster, T. Diao, I. Pappas and P. J. Chirik, ACS Catal., 2016, 6, 2632-2636; (k) A. D. Ibrahim, S. W. Entsminger, L. Zhu and A. R. Fout, ACS Catal., 2016, 6, 3589-3593; ( $l$ ) B. Raya, S. Biswas and T. V. RajanBabu, ACS Catal., 2016, 6, 6318-6323; ( $m$ ) W.-Y. Chu, R. GilbertWilson and T. B. Rauchfuss, Organometallics, 2016, 35, 2900-2914; (n) C. Wang, W. J. Teo and S. Ge, ACS Catal., 2017, 7, 855-863; (o) B. Raya, S. Jing, V. Balasanthiran and T. V. RajanBabu, ACS Catal., 2017, 7, 2275-2283; (p) Y. Liu and L. Deng, J. Am. Chem. Soc., 2017, 139, 1798-1801; (q) C. Wang, W. J. Teo and S. Ge, Nat. Commun., 2017, 8, 2258; (r) B. Cheng, P. Lu, H. Zhang, X. Cheng and Z. Lu, J. Am. Chem. Soc., 2017, 139, 9439-9442.

13 (a) A. Kuznetsov and V. Gevorgyan, Org. Lett., 2012, 14, 914917; (b) M. I. Lipschutz and T. D. Tilley, Chem. Commun., 2012, 48, 7146-7148; (c) V. Srinivas, Y. Nakajima, W. Ando, K. Satoa and S. Shimada, Catal. Sci. Technol., 2015, 5, 2081-2084; (d) V. Srinivas, Y. Nakajima, W. Ando, K. Sato and S. Shimada, J. Organomet. Chem., 2016, 809, 57-62; (e) I. Pappas, S. Treacy and P. J. Chirik, ACS Catal., 2016, 6, 4105-4109.

14 (a) R. J. Trovitch, Synlett, 2014, 25, 1638-1642; (b) X. Yang and C. Wang, Chem.-Asian J., 2018, DOI: 10.1002/ asia.201800618.

15 S. L. Pratt and R. A. Faltynek, J. Organomet. Chem., 1983, 258, C5-C8.

16 H. S. Hilal, M. Abu-Eid, M. Al-Subu and S. Khalaf, J. Mol. Catal., 1987, 39, 1-11.

17 H. S. Hilal, M. A. Suleiman, W. J. Jondi, S. Khalaf and M. M. Masoud, J. Mol. Catal., 1999, 144, 47-59.

18 W. Jondi, A. Zyoud, W. Mansour, A. Q. Husseinb and H. S. Hilal, React. Chem. Eng., 2016, 1, 194-203. 
19 C. Obradors, R. M. Martinez and R. A. Shenvi, J. Am. Chem. Soc., 2016, 138, 4962-4971.

20 J. S. Price, D. J. H. Emslie and J. F. Britten, Angew. Chem., Int. Ed., 2017, 56, 6223-6227.

21 J. H. Docherty, J. Peng, A. P. Dominey and S. P. Thomas, Nat. Chem., 2017, 9, 595-600.

22 J. R. Carney, B. R. Dillon, L. Campbell and S. P. Thomas, Angew. Chem., Int. Ed., 2018, 57, 10620-10624.

23 T. K. Mukhopadhyay, M. Flores, T. L. Groy and R. J. Trovitch, J. Am. Chem. Soc., 2014, 136, 882-885.

24 C. Ghosh, T. K. Mukhopadhyay, M. Flores, T. L. Groy and R. J. Trovitch, Inorg. Chem., 2015, 54, 10398.

25 T. K. Mukhopadhyay, C. Ghosh, M. Flores, T. L. Groy and R. J. Trovitch, Organometallics, 2017, 36, 3477-3483.

26 T. K. Mukhopadhyay, C. L. Rock, M. Hong, D. C. Ashley, T. L. Groy, M.-H. Baik and R. J. Trovitch, J. Am. Chem. Soc., 2017, 139, 4901-4915.

27 R. J. Trovitch, Acc. Chem. Res., 2017, 50, 2842-2852.

28 (a) J. Chai, H. Zhu, K. Most, H. W. Roesky, D. Vidovic, H.-G. Schmidt and M. Noltemeyer, Eur. J. Inorg. Chem., 2003, 4332-4337; (b) J. Chai, H. Zhu, H. W. Roesky, C. He, H.-G. Schmidt and M. Noltemeyer, Organometallics, 2004, 23, 3284-3289; (c) J. Chai, H. Zhu, H. Fan, H. W. Roesky and J. Magull, Organometallics, 2004, 23, 1177-1179; (d) J. Chai, H. Zhu, A. C. Stückl, H. W. Roesky, J. Magull, A. Bencini, A. Caneschi and D. Gatteschi, J. Am. Chem. Soc., 2005, 127, 9201-9206; (e) H. W. Roesky, M. S. Varonka and T. H. Warren, Inorg. Synth., 2010, 35, 34-38; $(f)$ S. Yao,
Y. Xiong and M. Driess, Chem.-Eur. J., 2012, 18, 1135611361; $(g)$ V. Yempally, W. Y. Fan, B. A. Arndtsen and A. A. Bengali, Inorg. Chem., 2015, 54, 11441-11449; (h) R. L. Webster, Dalton Trans., 2017, 46, 4483-4498; (i) M. M. Stalzer, T. L. Lohr and T. J. Marks, Inorg. Chem., 2018, 57, 3017-3024.

29 B. Cordero, V. Gómez, A. E. Platero-Prats, M. Revés, J. Echeverría, E. Cremades, F. Barragán and S. Alvarez, Dalton Trans., 2008, 2832-2838.

30 A. P. Golombek and M. P. Hendrich, J. Magn. Reson., 2003, 165, 33-48.

31 B. Epel, K. O. Schäfer, A. Quentmeier, C. Friedrich and W. Lubitz, J. Biol. Inorg Chem., 2005, 10, 636-642.

32 G. Friedmann, P. Sperry and J. Brossas, Eur. Polym. J., 1993, 39, 1197-1203.

33 K. Ouchi, M. Tsumura, H. Sakamoto, M. Fujita, M. Kuramoto and T. Miki, Jpn. Kokai Tokkyo Koho, JP2002341101A, 2002.

34 (a) S. Vijjamarri, V. K. Chidara and G. Du, ACS Omega, 2017, 2, 582-591; (b) S. Vijjamarri, S. Streed, E. M. Serum, M. P. Sibi and G. Du, ACS Sustainable Chem. Eng., 2018, 6, 2491-2494.

35 A. J. Chalk and J. F. Harrod, J. Am. Chem. Soc., 1965, 87, 1621.

36 Similar regioselectivity has been observed for Mn-catalyzed olefin hydroboration. See: G. Zhang, H. Zeng, J. Wu, Z. Yin, S. Zheng and J. C. Fettinger, Angew. Chem., Int. Ed., 2016, 55, 14369-14372. 